\title{
El ingreso de Francisco y Alonso Nieto de Herrera a la Compañía de Jesús
}

Silvana M. Lovay

\section{Recibido: 17 de mayo de 2013}

Evaluado: 18 de junio de 2013

Al incorporarse a la Compañía de Jesús, el escribano ${ }^{1}$ Alonso Nieto de Herrera hizo la renuncia de sus bienes a favor de los jesuitas el 24 de junio de $1643^{2}$. Este era uno de los pasos que se debía seguir para ingresar al Instituto ignaciano, consignado en el Capítulo Cuatro de las Constituciones. Aunque de ninguna manera el desprendimiento de los bienes temporales obligaba a hacerlos a favor de los jesuitas. En este instrumento público, Nieto de Herrera solicitó ser declarado "insigne bienhechor", consignando pasajes de su vida y sobre todo cada una de las propiedades que cedía en ese acto a la Compañía de Jesús, representada en la oportunidad por el rector del Colegio Máximo P. Diego de Boroa que había precedido como provincial, a quien por entonces ostentaba el cargo, el P. Francisco Lupercio Zurbano (1640-1645).

Estos bienes eran rurales y urbanos; entre los primeros estaba la estancia de Alta Gracia que incluía sus ganados, otra estancia llamada del Potrero que lindaba con aquella, otra con el nombre de Guamacha ${ }^{3}$ y 26 esclavos negros y negras incluyendo sus hijos, que servían a las haciendas. Entre las propiedades de la ciudad de Córdoba transfiere su casa, con su vestuario, alhajas y menaje de 170 marcos de plata, ubicada en la esquina noroeste de las callas Ituzaingó y San Jerónimo ${ }^{4}$, y un terreno más alejado (esquina nordeste de calles Sucre y Deán Funes). Todos estos bienes habían sido de sus dos esposas, especialmente de la dote de Estefanía de Castañeda, fallecida en 1623. Además entrega al

\footnotetext{
${ }^{1}$ El Consejo de Indias le concedió en 1621 el título de Escribano Público y de Hacienda Real y del Juzgado de Bienes Difuntos de la ciudad de Córdoba, rematado en 4.000 pesos (Tau Anzoátegui, 2000).

${ }^{2}$ Grenón, 1955: 409.

${ }^{3}$ Era un antiguo pueblo de indios ubicado en la banda sur del Río Segundo. Las tierras fueron otorgadas en merced en tres títulos, entre 1576 y 1591, junto con la encomienda de dichos indios, al granadino Blas de Peralta (1534-1592), casado con Catalina de Cabrera quien al enviudar contrajo segunda nupcias con Agustín Ruiz de Castilblanco. Las tierras fueron de la primera esposa de Nieto de Herrera y al pasar a la Compañía de Jesús, fueron vendidas a Luis Romero de Pineda en 1645 (Ferreyra, 2004: 29 y 130).

${ }^{4}$ Esta casa fue de su primera esposa Da. Estefanía de Castañeda. Tenía su entrada por calle San Jerónimo y varias tiendas, en la que en una de ellas vivía su hermana Da. Magdalena de Sotomayor y sus hijos. Una vez que quedó en propiedad de los jesuitas fue vendida a Agustín Soria en 3.700 pesos a fines de 1654 (Luque Colombres, 1980: 210).
} 
provincial la suma de 1.277 pesos $^{5}$. La mayoría de los inmuebles fueron enajenados por los jesuitas que solo conservaron la estancia de Alta Gracia para sustento de la universidad ${ }^{6}$. Inmediatamente iniciaron las construcciones, entre ellas una capilla, que para 1654 ordenaba desde Roma el general Goschwin Nickel (1652-1664) al provincial Juan Pastor que, por sugerencia del mismo coadjutor Nieto de Herrera, se hiciera otra "más capaz y decente" con un tabernáculo para su patrona ${ }^{7}$.

El P. Nicolás del Techo dejó escritas unas líneas de la vida de Nieto de Herrera en su conocida obra, recordando que a tan solo cuarentas días de enviudar ingresó a la Compañía, cuando contaba con 68 años de edad y que entró al Instituto "gracias a los consejos de su nieto". Equivoca aquí el parentesco pero sugiere lo que el resto de los documentos afirman, es decir que ingresó por influjo del joven sobrino Francisco Nieto ${ }^{8}$.

Nieto de Herrera fue hijo de Francisco Nieto y Catalina Medina, habiendo nacido en Garrobillas en $1574^{9}$. La Carta Anua del periodo $1641-1643^{10}$ brinda la noticia de su incorporación, afirmando que donó veinte mil pesos, por lo cual fue considerado "insigne bienhechor" y por tanto merecedor a esta privilegiada mención de su vida. Efectivamente y siguiendo las Constituciones, en la Parte Tercera, Capítulo Primero, se establecen dos rangos para quienes aportaban bienes a la Compañía. Básicamente: fundadores y bienhechores. El primero era quien dotaba de casa, con su ajuar; iglesia con todo lo necesario para el culto; biblioteca y sustento a un colegio, casa profesa, noviciado o convictorio, ofreciendo a cambio una misa mensual y una candela de cera a sus deudos el

\footnotetext{
${ }^{5}$ Grenón,1929: 25

${ }^{6}$ Page, 2000: 27.

${ }^{7}$ Se refiere a la virgen de Altagracia, denominación que el mismo Nieto de Herrera le había impuesto a la estancia y que los jesuitas conservaron. Pues el propietario de aquellos campos sin duda debía haber tenido particular devoción por esta virgen, patrona de Garrovillas, donde se levantó una ermita, en la antiguamente llamada dehesa de Villaluengo (Garrovillas) en el Siglo XV (Martín Gil, 1944: 147-160 y Paín Arias, 1997).

${ }^{8}$ Techo, 2005: 684-685.

${ }^{9}$ El P. Grenón (1955: 409) consigna que nació en Algarrobales de Alconétar en Extremadura, mientras que el P. Storni, siguiendo el catálogo público de 1656 establece que fue en Algarrobillo de Sevilla (Storni, 1980: 199). Luque Colombres finalmente aclara la cuestión afirmando que fue en Garrovillas de Alconétar en la provincia de Cáceres en la comunidad autónoma de Extremadura (Page, 2000: 26). Justamente en su noticia necrológica se expresa que era natural de Extremadura. Garrovillas fue para el Siglo XVI el tercer pueblo más grande de Cáceres, con título de villa otorgado por Alfonso X El Sabio. El archivo de la parroquia de Santa María de la Consolación se inicia en 1564 (aunque la construcción de la iglesia se sitúa entre 1494-1520) y la de San Pedro comienza en el año 1615, lo cual creemos fue bautizado en la primera iglesia. La bibliografía extremeña sobre los Nieto de Herrera es escasa. Navarro Caballero (1978: 243), y repiten algunos otros, expresa: "Alonso Nieto de Herrera. En un manuscrito del padre José Tamayo (1607-1685), existente en la Biblioteca de la Universidad de Salamanca, cuyo título es "Días memorables de la Compañía de Jesús" se habla de este ilustre garrovillano que, después de ejercer por bastantes años el cargo de escribano en el Paraguay, vistió con un sobrino suyo la sotana de Jesuita, dedicando el resto de su vida á la civilización de aquellos países. Murió en 1661 á los 94 años en Córdoba de Tuaunaus” (sic: Tucumán).

${ }^{10}$ Esta anua está firmada por el padre provincial Francisco Lupercio de Zurbano en Córdoba, el 22 de octubre de 1644. Varios acontecimientos importantes surgen de su lectura como la victoria de los guaraníes en Mbororé y los festejos del centenario de la Orden. Pero prevalecen los aspectos espirituales que en definitiva son la fórmula prescripta en Roma para un grupo de lectores que no se circunscribe exclusivamente a quien está dirigida, es decir el padre general Mucio Viteleschi. Fueron publicadas íntegramente por Ernesto J. A. Maeder (1996) y parcialmente por Page, 2004: 131.
} 
día de la fundación. El bienhechor era quien donaba bienes menores. En el caso de Nieto de Herrera el general Vicenzo Caraffa (1646-1649) lo agració como tal, concediéndole en toda la Compañía dos misas y dos coronas (rosario de cinco misterios) y tres misas y tres coronas para la Asistencia de España, es decir toda Hispanoamérica ${ }^{11}$.

Un expediente hallado en el Archivo General de Indias nos revela valiosa información desconocida hasta el momento sobre Alonso Nieto de Herrera. En la Villa Real de Garrovillas el vecino, escribano público y de número, Francisco Nieto de Herrera se presentó el 15 de febrero de 1610 ante el corregidor y justicia mayor de la ciudad don Pedro Maldonado Carpio, en nombre de su hermano Alonso Nieto de Herrera, residente por entonces en Indias e hijo legitimo del difunto escribano Francisco Nieto y Catalina Medina. El motivo era que el rey le otorgara el oficio de escribano real a su hermano Alonso.

Por lo tanto Francisco presentó una serie de vecinos como testigos, quienes darían fe de conocer a Alonso, para lo cual la mayoría testificó unánimemente: "limpio de raza de moro ni judío, ni de los nuevamente convertidos a nuestra santa fe católica, no penitenciado ni fue pasado por el santo oficio de la inquisición". A partir de las declaraciones se vislumbran una serie de datos hasta ahora inéditos sobre la figura de Alonso Nieto de Herrera. Expresa el extenso documento rubricado por varias personas que pasó a las Indias hacía más de diez años, es decir alrededor de $1600^{12}$, y por tanto al ser muy joven no estaba capacitado para el oficio, aunque "desde que tuvo uso de razón su oficio fue ejercitarse en escribir". Tenía vocación de escribano y para ello "algunos años se fue a la ciudad de Granada en donde recibió adiestramiento en oficios de escribanos de cámara”, de la Real Audiencia ${ }^{13}$ de esa ciudad. Luego volvió a Garrovillas y se fue a las Indias, insistiendo los testigos: "a más de diez años". Era muy joven pues ratifican todos que para esa fecha de 1610 tenía 33 años cumplidos, habiendo nacido en 1577 (fecha que se contradice con la conocida de 1574) que lo hacía tener para su partida 23 años de edad. Por ese entonces era público que residía en la ciudad de La Plata del virreinato del Perú (hoy Sucre, conocida como La Plata entre 1538 y 1776), por una carta que le escribió a su madre fechada el 30 de enero del año anterior.

También todos concuerdan en manifestar que Alonso poseía una hacienda heredada de su padre valuada en cincuenta mil maravedíes. Finalmente el corregidor eleva el expediente expresando que Alonso Nieto de Herrera tiene todas las calidades necesarias,

\footnotetext{
${ }^{11}$ Grenón, 1929: 28.

${ }^{12}$ En la sección del AGI de Pasajeros a Indias no encontramos registrado su nombre. Pues como escribe Navarro del Castillo, calcular el número de extremeños que pasaron a Indias entre 1493 y 1599 es imposible. De los 225.000 españoles que pasaron en el Siglo XVI solo 42.000 se han identificado. Extrañamente hallamos un tal Francisco Nieto, vecino de la Villa de Garrovillas y de oficio escribano público, que pasa a Indias en 1605 con su mujer María Gutiérrez y sus hijos Gaspar, Ana, María, Isabel, Juana de Herrera, y Francisco, Antonio, Mariano y Juan Nieto (AGI, Contratación, 5285, n ${ }^{\circ} 62$ 1605-04-06, Expediente de información y licencia de pasajero a indias de Francisco Nieto).

${ }^{13}$ La Real Chancillería o Audiencia de Granada fue creada por Isabel I de Castilla y funcionó allí entre 1505 y 1834. Su competencia jurídica alcanzaba el sur del río Tajo y su estructura administrativa estaba supeditada a los órganos de gobierno y de justicia. Esta última estaba compuesta de cuatro salas de lo civil, una para el crimen y otra para asuntos de hidalguía, alcabalas y tercias. Como órganos esenciales para el Tribual en su conjunto se destacan las escribanías especializadas en las materias que entendían las Salas. Precisamente en las cuatro salas en lo civil trabajaban los escribanos de cámara. Las escribanías que actuaban para el tribunal eran oficios públicos y hereditarios.
} 
expuestas por los testigos presentados, por lo que solicita se le otorgue el real título y le informe a la Real Audiencia de La Plata ${ }^{14}$.

Volviendo a la escritura de donación a los jesuitas, allí se expresa que por entonces contaba con 68 años, habiendo estado casado dos veces, pero sin descendencia, y que al fallecer su última esposa, la nacida en Gran Canaria doña Juana Solís Benavente ${ }^{15}$, se enteró que un sobrino suyo, hijo de su hermano Francisco, había arribado de España y quería unirse a la Compañía de Jesús. Por tanto "se resolvió dejar el mundo desengañado con la muerte de la mujer y ejemplo del sobrino”. Así lo hicieron ambos, ingresando al Noviciado.

Nuevamente se lo menciona en la Carta Anua del período $1659-1662^{\mathbf{1 6}}$, cuando se redacta su noticia necrológica, que da testimonio de cuando Alonso se embarcó a América y naufragó la nave apenas partió, quedando pocos sobrevivientes. Reitera que al fallecer su esposa ingresó a la Orden y "donó a nuestro colegio de Córdoba una respetable estancia, su rico mobiliario y numerosos esclavos”. El amplio texto apologético menciona especialmente su devota religiosidad y buen desempeño como escribano, agregando que ingresó "sin demora a nuestra casa, teniendo por compañero a un jovencito, hijo de su hermano, al cual había hecho venir de España, para que fuese su heredero". Efectivamente así lo hicieron y llegó a permanecer 21 años en la Compañía de Jesús, falleciendo nonagenario, luego de haber estado un año postrado.

El sobrino de Alonso Nieto de Herrera se llamaba -como dijimos- Francisco, y tenemos noticias suyas también a través de su obituario. Reitera que era de familia noble como también se menciona de Alonso. Francisco había nacido en Madrid en 1625 ingresando a la Compañía de Jesús el mismo día que su tío, cuando contaba con 18 años de edad. La Anua inédita del periodo $1663-1666^{17}$ también confirma que aquel, ya viudo, lo mandó llamar insistentemente para entregarle sus bienes. Al ver al joven "muy aplicado a los estudios y muy inclinado a la piedad y de una angelical inocencia. Así se le ocurrió a su tío, que sería mejor, que los dos abandonasen el mundo para entrar en religión”.

\footnotetext{
${ }^{14}$ AGI, Charcas, 65, $\mathrm{n}^{\circ}$ 10, 1610-03-22 Expediente de Confirmación del oficio de notario de las Indias a Alonso Nieto de Herrera. Resuelto

${ }^{15}$ Juana era viuda de don Juan Zambrano, posiblemente tuvo dos hermanas, pues provenían de Gran Canaria, llamadas María y Catalina. Esta última se había casado en primeras nupcias con Cristóbal de Estrada y luego con Francisco Mejía Mojica. Contrajo matrimonio por tercera vez con el capitán Francisco de Ayala y Murga, quien al enviudar ingresó a la Compañía de Jesús. Este último nació en Pamplona en 1592 incorporándose al Instituto en 1653, un día antes de morir (Luque Colombres, 1980: 158 y 219; Storni, 1980: 26).

${ }^{16}$ Contienen 30 fojas y están escritas y firmadas por el padre provincial Andrés de Rada quien las dirige al padre general Goschwin Nickel. El padre Rada supone que las cartas anteriores (1658-1660) se perdieron, por lo que al principio repite información de aquellas. Si bien están firmadas el 20 de enero de 1663 estima el padre Leonhardt que debe haber una equivocación ya que en el folio 115 se habla de las biografías ya publicadas de las que se encuentra la del padre Cataldino hecha en 1664. Pues entonces no duda en adjudicarle el año de 1665 (BCS, Cartas Anuas, 1659-1622, Estante 11).

${ }^{17}$ Esta Anua está escrita y firmada por el padre provincial Andrés de Rada y su sucesor el viceprovincial Francisco Jiménez que se mantuvo en su cargo entre 1665 y 1669. Consta de 29 fojas y es dirigida al padre general Goswino Nickel aunque las recibió su sucesor Pablo Oliva (BCS, Cartas Anuas, 1663-1666, Estante 11, f. 149).
} 
El joven concluyó el Noviciado en Córdoba con su tío, hizo los votos acostumbrados y terminó sus estudios, para luego ser ordenado sacerdote, cuando ya comenzaba a sufrir una molestia cólica crónica. En el catálogo de 1656 se menciona que tenía cursado sus tres años de filosofía y cuatro de teología en Córdoba ${ }^{18}$. Inmediatamente después fue enviado a las reducciones de guaraníes donde se abocó al estudio de la lengua indígena.

No conocemos bien su itinerario por las misiones, pero por el P. Storni sabemos que su cuarto voto lo profesó en la reducción de San Carlos de Guabirupá, el 6 de noviembre de $1661^{19}$. Esta actual ciudad de la provincia de Corrientes que mantuvo el nombre de la reducción, fue fundada con guaraníes en Caá Capí el año 1631, en las nacientes del río Aguapey. Su primer jesuita y fundador fue el P. Pedro de Mola (16021660), que profesó su cuarto voto en esta reducción. Al año siguiente de agrupada su población, contaba con 350 habitantes ${ }^{20}$. Fue destruida por la bandeira comandada por Francisco Bueno que entre 1637 y 1639 avanzó por el río Taguary arrasando San Carlos, Apóstoles, Caaré y Candelaria. El pueblo se trasladó en 1638 a su actual ubicación en la cabecera del río Aguapey, afluente del Uruguay, quedando a cargo del P. Francisco Jiménez (1602-1668) que por entonces profesaba su cuarto voto en Loreto. Para 1644 ya contaba con 2.300 habitantes a cargo de los PP. Pedro Álvarez y Juan Bautista Hornos ${ }^{21}$. En 1657 estaba al frente el chileno P. Francisco Ignacio de Molina (1593-1679) y el cacique corregidor y capitán de guerra Roque Tambataí, quienes declararon la presencia de 2.183 personas $^{22}$. El P. Molina debe haber recibido cuatro años después al P. Francisco Nieto en su reducción, y hasta lo habrá despedido pues permaneció en ella hasta su fallecimiento.

Luego de su paso por San Carlos, el P. Nieto debe haberse trasladado a la reducción de San José, pues allí falleció. Esta reducción fue fundada por el P. Antonio Ruiz de Montoya y Simón Maceta en 1625, entre el río Ivaí y el Tibagi en la región del Tucuty. Este último misionero se quedó en ella. Pero en 1631 se abandonó, ante el temor latente de los bandeirantes. Los evacuados se reunieron cerca de Loreto y en 1636 se refundó una nueva reducción con el mismo nombre en la región de Ycaroig. Quedó a cargo del P. José Cataldino, superior de las reducciones de guaraníes entre 1644 y $1646^{23}$. Posteriormente (según Anua de 1641-1643) quedó en ella el belga Luis Ernot (1597-1667) y el sardo Juan Antonio Manquiano (1603-1670). El primero trajo la devoción de Nuestra Señora de Fe (muy devota en Flandes). Para el año 1643 moría en la reducción el P. francés Pedro Marcq a la edad de 33 años $^{24}$. Al año siguiente el sardo fue reemplazado por el valenciano P. Pedro Cañigral (1607-1654). Ya contaba con una capilla, pues se habla de haberse enriquecido la sacristía. En la Anua 1645-1646 dice "el hermoso templo fue enriquecido con un artistico

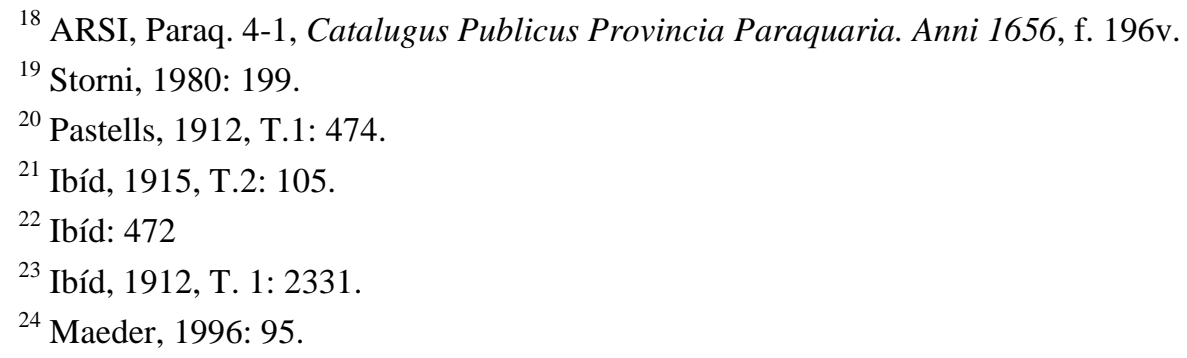


template sobre el altar mayor" 25 . Efectivamente se ratifica en la Anua siguiente de 16471649, donde se expresa "Se ha construido una Buena iglesia y la han adornado con primor. El retablo del altar mayor es elegante, tiene la forma de un templo Coronado encima de las columnas doradas con hermosos capiteles. En el centro se halla el lienzo que representa al celestial patron de este pueblo, obra de nuestro pintor flamenco" 26 . Se refiere a Berger. En esta reducción falleció varios años después el famoso jesuita Antonio Sepp en 1733.

De tal modo que el P. Francisco Nieto estaba a la sazón en el pueblo de San José, cuando por un resfrío cayó enfermo de pulmonía y falleció. La Anua repite que había presentido su final y por ello había hecho los Ejercicios y una prolongada confesión. Cuenta a su vez que convaleciente su superior le decía que "pronto se iba a bendecir la iglesia nueva", respondiéndole que él ya "no tendría la dicha de presenciarlo". Lo que hace suponer que aquella iglesia fue reemplazada.

Expresa la Anua una serie de virtudes del sacerdote que se había declarado "a sus superiores conforme para cualquier trabajo apostólico". Tal es así que solo tres días antes de morir le había escrito al visitador y provincial Andrés de Rada (1663-1669), ofreciéndose para ir a la misión de Itatí, donde se pedía un nuevo contingente de misioneros. Carta que llegó junto con la noticia de su muerte, lo que la hizo más dolorosa al provincial y sus compañeros.

Finalmente como casi todos los obituarios se mencionan los años que tenía y los que pasó en la Compañía: "Había pasado los 38 años de edad, los 24 de Compañía y los 4 de profesión de cuatro votos, muriendo el 31 de diciembre de 1666”.

No mucho más sabemos de este joven que influenció para que el prestigioso y respetado escribano Alonso Nieto de Herrera ingresara a la Compañía de Jesús y entregara sus bienes, uno de los cuales, la estancia de Alta Gracia, hoy se conserva en su plenitud.

\section{Archivos}

Archivo General de Indias, Sevilla (AGI)

Archivo Romano de la Compañía de Jesús, Roma (ARSI)

Biblioteca del Colegio del Salvador, Buenos Aires (BCS)

\section{Bibliografía}

Ferreyra, María del Carmen (2004), Las Estancias del Río Segundo 1573-1700, Córdoba, Junta Provincial de Historia de Córdoba ${ }^{\circ} 24$.

Grenón SI, Pedro (1955), "Las renuncias de bienes en la provincia del Paraguay. Siglo XVII”, Archivum Historicum Societatis Iesu, Roma, no 24.

\footnotetext{
${ }^{25}$ Ibíd: 47.

${ }^{26}$ Ibíd: 108.
} 
Grenón SJ, P. (1929), Documentos Históricos Alta Gracia Primera Parte, Córdoba: Talleres Gráficos de la Penitenciaría.

Luque Colombres, Carlos A. (1980), Orígenes históricos de la propiedad urbana de Córdoba (Siglos XVI y XVII), Córdoba: Universidad Nacional de Córdoba, Instituto de Estudios Americanistas.

Maeder, Ernesto J. A. (1996), Cartas Anuas de la provincia jesuítica del Paraguay 16411643, Resistencia: Instituto de Investigaciones Geohistóricas.

Martín Gil. Tomás (1933), "Excursiones a viejas ermitas”, Revista del Centro de estudios extremeños, $\mathrm{n}^{\circ} 2$, Mayo-Agosto, Diputación de Badajoz.

Navarro del Castillo, Vicente (1978), La epopeya de la raza extremeña en Indias, Mérida.

Page, Carlos A. (2000), La estancia jesuítica de Alta Gracia, Córdoba: Universidad Católica y Nacional de Córdoba.

Page, Carlos A. (2004), El Colegio Máximo de Córdoba (Argentina) según las Cartas Anuas de la Compañía de Jesús, Córdoba: BR Copias.

Paín Arias, María Altagracia (1997), La virgen de Altagracia a través de la geografía hispano americana, Garrovillas: ed. Autor.

Pastells SJ, Pablo (1912-1915), Historia de la Compañía de Jesús de la Provincia del Paraguay (Argentina, Paraguay, Uruguay, Perú, Bolivia y Brasil), según los documentos originales del Archivo General de Indias, Madrid: Librería General de Victoriano Suárez, Tomo 1 y 2.

Storni SI, Hugo (1980), Catálogo de los jesuitas de la provincia del Paraguay (Cuenca del Plata) 1585-1768), Roma: Historicum Societatis Iesu.

Tau Anzoátegui, Víctor (2000), Libros registros-cedularios del Tucumán y Paraguay, 1573-1716. Catálogo, Buenos Aires: Instituto de Investigaciones de Historia del Derecho.

Techo, Nicolás del (2005), Historia de la Provincia del Paraguay de la Compañía de Jesús, Asunción: Centro de Estudios Paraguayos “Antonio Guasch”. 